\title{
Genetic Variability within ADA Gene Region and Infertility in Subjects with Varicocele
}

\begin{abstract}
Keywords: ADA gene; Varicocele; Infertility
Abstract

A role of adenosine deaminase in male fertility is suggested by the presence of adenosine receptors in the acrosomal region of spermatozoa and in the epithelium of vas deferens. A relationship between ADA enzymatic activity and fertility in men has also been reported.

We have carried a genetic study on three polymorphic sites (ADA 1, ADA2 and ADA6) within the ADA gene in relation to varicocele and infertility in 136 men who were referred to the clinic for varicocele and in 246 blood donors as controls. ADA sites were studied by DNA analysis.

Subjects homozygote for the three more common alleles present in the ADA sites considered $\left(\operatorname{ADA} 1^{*} 1 /{ }^{*} 1, \operatorname{ADA} 2 * 1 /{ }^{*} 1\right.$ and $\left.\operatorname{ADA} 6 * 2 /{ }^{*} 2\right)$ were more frequent among subjects with varicocele than among controls (OR $=1.834,95 \%$ C.I. 1.122-2.996). This phenomenon was much more marked in infertile than in fertile subjects. Subjects with this joint genotype displayed the lowest value of rectilinear sperm motility: such motility was the lowest among infertile subjects carrying the triple homozygous genotype.

Many polymorphic sites have been detected within the ADA gene. It is likely that ADA variability may influence not only its enzymatic activity but also its function as an ecto-enzyme which could affect fertility in man.
\end{abstract}

\section{Introduction}

Several lines of evidence suggest an important role of adenosine in male reproductive functions. Adenosine receptors and ecto-adenosine deaminase are present in the acrosomal and equatorial region of human spermatozoa and inhibition of ADA activity improves sperm fertilization [1,2]. The epithelium of vas deferens plays an important role in conditioning the environment to which the sperm is exposed prior to its ejaculation. This epithelium expresses adenosine receptors that contribute to modulate anion secretion [3]. Recently a statistically significant relationship has been observed between plasma activity of ADA isoenzymes and fertility in men suggesting an important effect of ADA activity on fertility $[4,5]$.

\section{Adenosine deaminase genetic polymorphisms}

Adenosine Deaminase (ADA) is a polymorphic enzyme that irreversibly deaminates adenosine to inosine thus contributing to the regulation of intracellular and extracellular concentrations of adenosine. The ADA gene is localized on human chromosome $20 \mathrm{q} 13.11$ and consists of 12 exons spanning approximately $32 \mathrm{~Kb}$ of DNA [6]. A high number of differences among normal sequences have been found through the coding and intronic regions of the gene [7]. It is unknown at present if such ADA genetic variability affects its enzymatic activity and its interaction with ADA binding proteins.

Adenosine regulates glucose metabolism and immunological functions. High ADA activity is associated to low concentration of adenosine resulting in low engagement of adenosine receptors and in

\section{Journal of}

Andrology \& Gynaecology

Gentile $\mathbf{V}^{1}$, Nicotra $\mathbf{M}^{1}$, Bottini $\mathrm{E}^{2}$, Gloria-Bottini $\mathrm{F}^{2^{*}}$, Modafferi $\mathrm{F}^{3}$ and Gentile $\mathrm{G}^{4}$

${ }^{\prime}$ Department of Gynecology, Obstetrics and Urologic Science, University La Sapienza, Rome, Italy

${ }^{2}$ Department of Biomedicine and Prevention, University of Tor Vergata, Rome, Italy

${ }^{3}$ S.M. Goretti Hospital, ASL Latina, Italy

${ }^{4}$ Department of Urologic Surgery, A. Gemelli Hospital, Rome, Italy

\section{*Address for Correspondence}

Fulvia Gloria-Bottini, MD, Department of Biomedicine and Prevention, University of Tor Vergata, Via Montpellier 1, 00133 Roma, Italy, Tel: +39 06 30889514; E-mail: gloria@med.uniroma2.it

Submission: 25 April, 2016

Accepted: 01 June, 2016

Published: 06 June, 2016

Copyright: (c) 2016 Gentile V, et al. This is an open access article distributed under the Creative Commons Attribution License, which permits unrestricted use, distribution, and reproduction in any medium, provided the original work is properly cited.

Reviewed \& Approved by: Dr. Hooman Sadri-Ardekani, Avicenna Research Institute (ARI), Tehran, Iran

turn into a weaken $\mathrm{T}$ cell activation and increased glucose tolerance. On the contrary, low ADA activity is associated to high adenosine concentration resulting in high engagement of adenosine receptors and in turn to strengthen $\mathrm{T}$ cell activation and decreased glucose tolerance. The possible consequences at the clinical level of the "normal" genetic variability of ADA have not been addressed.

ADA was supposed to be an exclusively cytosolic enzyme until the demonstration that it is present on the surface of many cell as an ecto-enzymes [8]. The functional role of ecto-ADA consists mostly in the local degradation of extracellular adenosine: ADA is also able to transduce signals through its interaction with CD26 or A1R, two ADA-anchoring proteins. In this way it acts as a costimulatory molecule, which facilitates a variety of specific signaling events in different cell types [8]. Quantitatively, the strength of the transduced signal would depend upon the concentration of ecto-ADA available.

We have studied three intragenic adenosine deaminase polymorphisms $\left(\mathrm{PCRP}_{\mathrm{s}}\right.$ ) in a sample of subjects with varicocele. The three PCRP spanning approximately over $28 \mathrm{~Kb}$ have a known molecular basis and include the presence/absence of a Taq I site $\left(\mathrm{ADA}_{1}\right)$ (nt 4050-4053, exon 1), of a Pst I site $\left(\mathrm{ADA}_{2}\right)$ (nt 1946519470, intron 2) and of a MlnN I site (ADA 6 ) (nt 31230-31235, exon 6) [7]. The Taq I PCRP at exon 1 corresponds to a G > A transition at nt 4052 and leads to the substitution of asparagine for aspartic acid at codon 8 [9]. The Asp8Asn mutation is the molecular genetic basis for the biochemical polymorphism at the ADA locus reported by Spencer et al. with two common alleles $\mathrm{ADA}^{\star} 1$ and $\mathrm{ADA}^{\star} 2$ [10].

Since ADA has an important role in the regulation of adenosine concentration in body fluids and in signal transduction events, its genetic polymorphism may influence the susceptibility and/or the clinical course of human diseases. 
Citation: Gentile V, Nicotra M, Bottini E, Gloria-Bottini F, Modafferi F, et al. Genetic Variability within ADA Gene Region and Infertility in Subjects with Varicocele. J Androl Gynaecol. 2016;4(1): 4

In this paper we have investigated the relationship between the genetic variability of ADA gene and male infertility in a sample of men with varicocele.

\section{Material and Methods}

One hundred and thirty six subjects with varicocele admitted consecutively in the Outpatient Department were studied: 77 were infertile. Diagnosis of varicocele was made by Doppler ultrasonography. Mean grade of varicocele was $2.75( \pm 0.11)$ in fertile and $2.83( \pm 0.11)$ in infertile men; mean age was 27.16 years $( \pm 0.84$ ) in fertile and 37.90 years $( \pm 0.75)$ in infertile man; 246 fertile blood donors without varicocele were studied as controls (mean age 34.2 years \pm 1.20 ). All subjects gave verbal informed consent to participate in the study that was approved by the Council of Department.

ADA genotypes were determined by PCR. Genomic DNA was extracted from venous blood samples collected in NaEDTA. PCR amplification was carried out as described by Hirschhorn et al. with slight modifications [9]. Briefly, the PCR volume was $25 \mu \mathrm{l}$ containing $100 \mathrm{ng}$ of DNA, $1.5 \mathrm{mM} \mathrm{MgCl}_{2}, 2.5 \mathrm{x}$ reaction buffer, 5 pmoles of each primer, $50 \mathrm{mM}$ each dNTP, $2 \mathrm{U}$ of Supertherm DNA polymerase (LPI FISCHER). Thirty cycles $\left(1 \mathrm{~min}\right.$ at $95^{\circ} \mathrm{C}, 1 \mathrm{~min}$ and $30 \mathrm{sec}$ at $65^{\circ} \mathrm{C}, 2$ min at $72{ }^{\circ} \mathrm{C}$ ) were performed using a DNA Thermal Cycler (Perkin Elmer).

Sense and antisense (forward and reverse) primers for the 4052 Taq I polymorphism (indicated as $\mathrm{ADA}_{1}$ locus) were respectively:

\section{5'ACCGAGCCGGCAGAGACCCAC-3'}

\section{5'-ACTTGACAGACAGCGAAACTGAGACCCAGA-3'}

Sense and antisense primers for the 19465 Pst I polymorphism (indicated as $\mathrm{ADA}_{2}$ locus) were respectively:

\section{5'GAGCACAAGCTTTGGAATTGGGCTTGGGTT-3'}

\section{5'ACACCAGGAGGACAAGACTCAGAGGCCCAGAA-3'}

Sense and antisense primers for the 31230 MluN I polymorphism (indicated as $\mathrm{ADA}_{6}$ locus) were respectively:

\section{5’-CATAGCAGTTAGGATTTGAAGACACTGAGCCC-3'}

\section{5’-AGGAGACACCATGGTCCCTGGTTCTTGTGAT-3’}

$7 \mu$ of each reaction was digested in $2 U$ of the specific enzyme according to manufacturer's directions. Each digestion was resolved on 3\% agarose gel in TAE (Tris/acetate/EDTA) buffer $\mathrm{pH}$ 8.0. Following electrophoresis, the gel was stained with ethidium bromide and the fragments were visualized by UV.

The three sites studied show each 2 alleles $\left(\mathrm{ADA}_{1}{ }^{\star} 1\right.$ and $\mathrm{ADA}_{1}{ }^{\star} 2$, $\mathrm{ADA}_{2}{ }^{\star} 1$ and $\mathrm{ADA}_{2}{ }^{\star} 2, \mathrm{ADA}_{6}{ }^{\star} 1$ and $\left.\mathrm{ADA}_{6}{ }^{*} 2\right): \mathrm{ADA}_{1}^{*} 1$ is more frequent than $\mathrm{ADA}_{1}{ }^{\star} 2, \mathrm{ADA}_{2}{ }^{\star} 1$ is more frequent than $\mathrm{ADA}_{2}{ }^{\star} 2$ and $\mathrm{ADA}_{6}{ }^{\star} 2$ is more frequent than $\mathrm{ADA}_{6}{ }^{\star} 1$ ).

The alleles corresponding to the presence and absence of the restriction sites have been indicated as allele 1 and allele 2 respectively.

Table 1: Distribution of ADA loci in men with varicocele and in controls

\begin{tabular}{|c|c|c|c|c|}
\hline \multicolumn{5}{|c|}{ Varicocele } \\
\hline & Infertile & Fertile & Total & Controls \\
\hline \multicolumn{5}{|c|}{$\mathrm{ADA}_{1}$} \\
\hline 1 & $61(79.2 \%)$ & $50(84.7 \%)$ & $111(81.6 \%)$ & 199 (80.9\%) \\
\hline $2-1$ & $15(19.5 \%)$ & $8(13.6 \%)$ & $23(16.9 \%)$ & $42(17.1 \%)$ \\
\hline 2 & $1(1.3 \%)$ & $1(1.7 \%)$ & $2(1.5 \%)$ & $5(2.0 \%)$ \\
\hline Total & 77 & 59 & 136 & 246 \\
\hline \multicolumn{5}{|c|}{$\begin{array}{l}\text { Chi square test of independence } \\
\text { Fertile vs Infertile } p=0.653 \\
\text { Varicocele vs Controls } p=0.923\end{array}$} \\
\hline \multicolumn{5}{|c|}{$\mathrm{ADA}_{2}$} \\
\hline 1 & $54(70.1 \%)$ & $34(57.6 \%)$ & $88(64.7 \%)$ & $128(52.0 \%)$ \\
\hline $2-1$ & $20(26.0 \%)$ & $20(33.9 \%)$ & $40(29.4 \%)$ & $92(37.4 \%)$ \\
\hline 2 & $3(3.9 \%)$ & $5(8.5 \%)$ & $8(5.9 \%)$ & $26(10.6 \%)$ \\
\hline Total & 77 & 59 & 136 & 246 \\
\hline \multicolumn{5}{|c|}{$\begin{array}{l}\text { Chi square test of independence } \\
\text { Fertile vs Infertile } p=0.200 \\
\text { Varicocele vs Controls } p=0.054\end{array}$} \\
\hline \multicolumn{5}{|c|}{$\mathrm{ADA}_{6}$} \\
\hline 1 & $8(10.4 \%)$ & $2(3.4 \%)$ & $10(7.4 \%)$ & $9(3.6 \%)$ \\
\hline $2-1$ & $17(22.1 \%)$ & $19(32.2 \%)$ & $36(26.5 \%)$ & $72(29.3 \%)$ \\
\hline 2 & $52(67.5 \%)$ & $38(64.4 \%)$ & $90(66.2 \%)$ & $164(66.7 \%)$ \\
\hline Total & 77 & 59 & 136 & 246 \\
\hline \multicolumn{5}{|c|}{$\begin{array}{l}\text { Chi square test of independence } \\
\text { Fertile vs Infertile } p=0.106 \\
\text { Varicocele vs Controls } p=0.408\end{array}$} \\
\hline
\end{tabular}


Citation: Gentile V, Nicotra M, Bottini E, Gloria-Bottini F, Modafferi F, et al. Genetic Variability within ADA Gene Region and Infertility in Subjects with Varicocele. J Androl Gynaecol. 2016;4(1): 4

Table 2: ADA loci joint distribution in men with varicocele and in controls. $\mathrm{ADA}_{1}{ }^{*} 1 /{ }^{*} 1 ; \mathrm{ADA}_{2}{ }^{*} 1 /{ }^{*} 1 ; \mathrm{ADA}_{6}^{*} 2 / * 2$ are the common genotypes.

\begin{tabular}{|l|c|c|c|c|}
\hline & \multicolumn{3}{|c|}{ Varicocele } & \\
\cline { 2 - 5 } & Infertile (1) & Fertile (2) & Total (3) & Controls (4) \\
\hline $\begin{array}{l}\text { No common genotype } \\
\text { (a) }\end{array}$ & $4(5.2 \%)$ & $3(5.1 \%)$ & $7(5.1 \%)$ & $15(6.1 \%)$ \\
\hline $\begin{array}{l}1 \text { common genotype } \\
\text { (b) }\end{array}$ & $16(20.8 \%)$ & $15(25.4 \%)$ & $31(22.8 \%)$ & $91(37.0 \%)$ \\
\hline $\begin{array}{l}\text { 2 common genotypes } \\
\text { (c) }\end{array}$ & $26(33.8 \%)$ & $25(42.4 \%)$ & $51(37.5 \%)$ & $89(36.2 \%)$ \\
\hline $\begin{array}{l}3 \text { common genotypes } \\
\text { (d) }\end{array}$ & $31(40.3 \%)$ & $16(27.1 \%)$ & $47(34.6 \%)$ & $51(20.7 \%)$ \\
\hline Total & 77 & 59 & 136 & 246 \\
\hline
\end{tabular}

Chi square test of independence

Infertile vs controls ( 1 vs 4 ) $p=0.0034$

Fertile vs controls ( 2 vs 4$) p=0.3490$

Varicocele vs controls ( 3 vs 4$) p=0.0098$

Odds Ratio analysis [d vs $(a+b+c)]$ O.R C.I.

All subjects with varicocele vs controls 1.834 1.122-2.996

Infertile vs controls 2.577 1.433.4.632

Fertile vs controls $0.6930 .336-1.417$

Genotyping determinations were made in groups of twenty samples including cases and controls in order to eliminate possible errors due to incomplete enzymatic digestion.

Statistical analyses were carried out by commercial software (SPSS).

\section{Results}

Table 1 shows the distribution genotypes of the three ADA loci in men with varicocele and in controls. A borderline statistically significant difference between varicocele and controls is observed for the $\mathrm{ADA}_{2}$ locus only. The decrease of carriers of $\mathrm{ADA}_{2}{ }^{\star} 2$ allele was more marked among infertile men.

In Table 2 we have calculated a cumulative parameter as an indicator of the number of rare alleles in the ADA gene. For each locus we have considered as fundamental the allele with highest frequency in the population i.e. allele ${ }^{\star} 1$ for the $\mathrm{ADA}_{1}$ and $\mathrm{ADA}_{2}$ loci and allele ${ }^{\star} 2$ for the $\mathrm{ADA}_{6}$ locus. Therefore in individuals with the joint genotype "ADA ${ }_{1}^{*} 1 /{ }^{\star} 1, \mathrm{ADA}_{2}{ }^{*} 1 /{ }^{\star} 1, \mathrm{ADA}_{6}{ }^{*} 2 /{ }^{*} 2$ " the parameter has a value $=0$ while in individuals carrying the rare alleles at all loci the parameter has a value $=3$. Since homozygotes for the less frequent alleles are rare, the great majority of carriers of these alleles are heterozygote. Therefore the parameter is an indicator of the degree of heterozygosity. The parameter displayed a highly significant difference between varicocele and control. A marked increase of the class with three common genotypes was observed in varicocele as compared to control. This increase was much more marked in infertile than in fertile subjects.

We have also assessed spermatic parameters in relation to single ADA genotypes. No statistically significant difference in sperm concentration and atypical spermatozoa was observed among genotypes of $\mathrm{ADA}_{1}, \mathrm{ADA}_{2}$ and $\mathrm{ADA}_{6}$. No statistically significant difference in rectilinear sperm motility and abnormal sperm motility was observed among $\mathrm{ADA}_{1}$ and $\mathrm{ADA}_{2}$ genotypes). A borderline difference in the last two parameters (respectively $p=0.03$ for rectilinear motility and $\mathrm{p}=0.05$ for proportion of spermatozoa with abnormal mobility) was observed among $\mathrm{ADA}_{6}$ genotypes (data not shown).

Table 3 shows the value of spermatic parameters in relation to the number of more common genotypes at the ADA loci. Rectilinear motility showed a statistically significant correlation with the number of rare alleles present at the ADA gene. The lowest motility was observed in subjects carrying all three common genotypes. As shown in Table 4, this decrease in motility was very marked and statistically significant in infertile men only. In these subjects a high value of eta squared was observed suggesting that more than $20 \%$ of the variance of rectilinear motility was due to the ADA genetic variability.

\section{Discussion}

Our data suggest that genetic variability within the ADA gene influences susceptibility to varicocele, sperm parameters and fertility. The study of three polymorphic sites in ADA gene has shown that subjects homozygote for the three common alleles at all these sites are more susceptible to varicocele; moreover in infertile subjects with this genotype rectilinear spermatozoa motility is drastically reduced. Overall, these observations suggest a heterozygote advantage.

A role of adenosine deaminase in male fertility is suggested by the presence of adenosine receptors in the acrosomal region of spermatozoa and in the vas deferens epithelium; moreover recent data have shown a relationship between ADA isoenzyme activity

Table 3: Spermatic Parameters in relation to the number of more common genotypes present in the ADA locus.

\begin{tabular}{|c|c|c|c|c|c|c|c|c|}
\hline & \multicolumn{2}{|c|}{ Spermatic concentration } & \multicolumn{2}{|c|}{ Atypical spermatozoa } & \multicolumn{2}{|c|}{ Rectilinear motility } & \multicolumn{2}{|c|}{ Abnormal motility } \\
\hline & Mean & S.E & Mean & S.E & Mean & S.E & Mean & S.E \\
\hline No common genotype (a) & 34.6 & 11.9 & 72.9 & 5.2 & 36.2 & 9.1 & 7.5 & 1.4 \\
\hline 1 common genotype (b) & 53.8 & 10.2 & 76.5 & 2.3 & 31.7 & 3.1 & 12.6 & 1.9 \\
\hline 2 common genotypes (c) & 45.0 & 5.8 & 70.5 & 3.2 & 32.7 & 2.3 & 10.6 & 1.4 \\
\hline 3 common genotypes (d) & 50.1 & 8.8 & 68.5 & 3.4 & 23.9 & 2.1 & 16.1 & 2.6 \\
\hline \multicolumn{9}{|c|}{$\begin{array}{c}\text { Significance of difference } \\
\text { a vs b vs c vs d }\end{array}$} \\
\hline Variance analysis & \multicolumn{2}{|c|}{$p=0.760$} & \multicolumn{2}{|c|}{$p=0.388$} & \multicolumn{2}{|c|}{$p=0.032$} & \multicolumn{2}{|c|}{$p=0.205$} \\
\hline Linear correlation & \multicolumn{2}{|c|}{$p=0.848$} & \multicolumn{2}{|c|}{$p=0.138$} & \multicolumn{2}{|c|}{$p=0.013$} & \multicolumn{2}{|c|}{$p=0.110$} \\
\hline \multicolumn{9}{|c|}{$(a+b+c)$ vs $d$} \\
\hline Student t & \multicolumn{2}{|c|}{$p=0.767$} & \multicolumn{2}{|c|}{$p=0.245$} & \multicolumn{2}{|c|}{$p=0.004$} & \multicolumn{2}{|c|}{$p=0.096$} \\
\hline
\end{tabular}


Citation: Gentile V, Nicotra M, Bottini E, Gloria-Bottini F, Modafferi F, et al. Genetic Variability within ADA Gene Region and Infertility in Subjects with Varicocele. J Androl Gynaecol. 2016;4(1): 4

ISSN: $2332-3442$

Table 4: Spermatozoa rectilinear motility in relation to the number of more common genotypes present in the ADA locus in fertile and infertile men.

\begin{tabular}{|c|c|c|c|c|}
\hline & \multicolumn{2}{|c|}{ Fertile } & \multicolumn{2}{|c|}{ Infertile } \\
\hline & Mean & S.E & Mean & S.E \\
\hline No common genotype (a) & 38.0 & 10.9 & 32.5 & 22.5 \\
\hline 1 common genotype (b) & 32.7 & 2.9 & 30.5 & 6.1 \\
\hline 2 common genotypes (c) & 30.7 & 3.5 & 34.7 & 2.9 \\
\hline 3 common genotypes (d) & 28.9 & 2.5 & 15.4 & 2.6 \\
\hline \multicolumn{5}{|c|}{$\begin{array}{c}\text { Significance of difference } \\
\text { a vs b vs c vs d }\end{array}$} \\
\hline Variance analysis & \multicolumn{2}{|c|}{$p=0.633$} & \multicolumn{2}{|c|}{$p=0.005$} \\
\hline Linear correlation & \multicolumn{2}{|c|}{$p=0.214$} & \multicolumn{2}{|c|}{$p=0.013$} \\
\hline Eta squared & \multicolumn{2}{|c|}{0.026} & \multicolumn{2}{|c|}{0.235} \\
\hline \multicolumn{5}{|c|}{$(a+b+c)$ vs d } \\
\hline Student t & \multicolumn{2}{|c|}{$p=0.364$} & \multicolumn{2}{|c|}{$p=0.000$} \\
\hline Eta squared & \multicolumn{2}{|c|}{0.013} & \multicolumn{2}{|c|}{0.225} \\
\hline
\end{tabular}

and fertility in men. Our genetic analysis of ADA genomic area in relation to varicocele and infertility is consistent with this reported relationship.

Besides the Asp8Asn variation in exon 1 of $\mathrm{ADA}$ gene, it is possible that also other polymorphic sites contribute to ADA activity and in turn to adenosine concentration. We have studied only three polymorphic sites in the ADA gene: many other polymorphic sites are present in this area; their possible influences on ADA functions in human metabolism and immune reactions are at present unknown. It is likely that these polymorphic sites have also a role in modulating ADA ecto-enzyme functions influencing the interaction of ADA molecule with cell surface proteins.

The relative low number of subjects examined represents a limitation of our study. However, the relationship between genetic variability within the ADA gene and both infertility and spermatic rectilinear motility is highly significant and suggests that further investigation in this area would be rewarding.

\section{References}

1. Minelli A, Allegrucci C, Piomboni P, Mannucci R, Lluis C, et al. (2000) Immunolocalization of $\mathrm{A} 1$ adenosine receptors in mammalian spermatozoa. J Histochem Cytochem 48: 1163-1171.

2. Monks NJ, Fraser LR (1988) Inhibition of adenosine-metabolizing enzymes modulates mouse sperm fertilizing ability: a changing role for endogenously generated adenosine during capacitation. Gamete Res 21: 267-276.

3. Carlin RW, Lee JH, Marcus DC, Schultz BD (2003) Adenosine stimulates anion secretion across cultured and native adult human vas deferens epithelia. Biol Reprod 68: 1027-1034.

4. Rostampour F, Biglari M, Vaisi-Raygani A, Salimi S, Tavilani H (2012) Adenosine deaminase activity in fertile and infertile men. Andrologia $44 \mathrm{Suppl}$ 1: 586-589.

5. Fattahi A, Khodadadi I, Amiri I, Latifi Z, Ghorbani M, et al. (2015) The Role of G22 A Adenosine deaminase 1 gene polymorphism and the activities of ADA isoenzymes in fertile and infertile men. Urology 86: 730-734.

6. Wiginton DA, Kaplan DJ, States JC, Akeson AL, Perme CM, et al. (1986) Complete sequence and structure of the gene for human adenosine deaminase. Biochemistry 25: 8234-8244

7. Tzall S, Ellenbogen A, Eng F, Hirschhorn R (1989) Identification and characterization of nine RFLPs at the adenosine deaminase (ADA) locus. Am J Hum Genet 44: 864-875.

8. Franco R, Casado V, Ciruela F, Saura C, Mallo J, et al. (1997) Cell surface adenosine deaminase: much more than an ectoenzyme. Prog Neurobiol 52 : 283-294.

9. Hirschhorn R, Yang DR, Israni A (1994) An Asp8Asn substitution results in the adenosine deaminase (ADA) genetic polymorphism (ADA 2 allozyme): occurrence on different chromosomal backgrounds and apparent intragenic crossover. Ann Hum Genet 58: 1-9.

10. Spencer N, Hopkinson DA, Harris H (1968) Adenosine deaminase polymorphism in man. Ann Hum Genet 32: 9-14. 